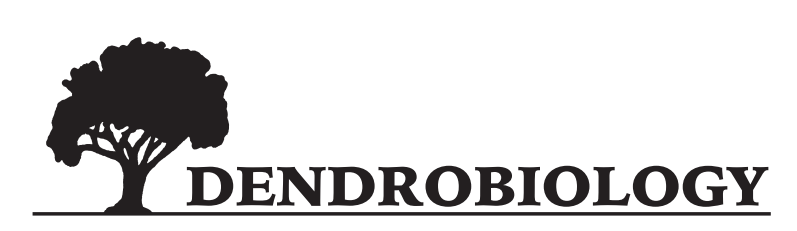

2016, vol. 76, 157-164

http://dx.doi.org/10.12657/denbio.076.015

\author{
Mason T. MacDonald, Rajasekaran R. Lada*, Rachel R. West, \\ Karen L. Nelson
}

\title{
Xylem-fed maple sap accelerates balsam fir needle abscission and but can delay water loss in spring and autumn
}

\author{
Received: 9 February 2016; Accepted: 9 August 2016
} Funding provided by Natural Science and Engineering Research Council, Atlantic Innovation Fund, ACOA,
Christmas Tree Council of Nova Scotia, NS Department of Natural Resources.

\begin{abstract}
Postharvest balsam fir trees are known to suffer a number of problems that may be linked to abscission rates, such as dehydration or wounding. By definition, postharvest balsam fir trees are also detached from roots and will no longer be supplied certain root derived factors normally translocated via the xylem. Resupplying those root derived factors may delay abscission. The objective of this experiment was to take sap from a root intact species (i.e. Acer saccharum L) and add it to the water supply of balsam fir branches. Further, the effect of reverse osmosis and autoclaving the sap supply will be explored. The experiment was conducted once in spring and again in autumn to examine seasonal changes in needle abscission. The only hormones found in the maple sap were ABA and its metabolites, with PA (163.0 ng g $\left.{ }^{-1}\right)$ being the primary metabolite present. Needle retention was higher in branches harvested in autumn, as long as they were provided a sap that did not undergo RO. If the sap had undergone RO, then needle retention was slightly decreased in autumn. Needle retention generally decreased as the concentration of maple sap in the water supply increased and this trend was accelerated if the sap had undergone RO. Autoclaving the sap successfully delayed the length of time for water consumption to decrease, but this unexpectedly did not translate into improved needle retention.
\end{abstract}

Keywords: Abscisic acid, Abies balsamea, needle retention, water content, water uptake

Address: M.T. MacDonald, R.R. Lada, R.R. West, K.L. Nelson, Christmas Tree Research Center, Faculty of Agriculture, Dalhousie University, Truro, NS, B6L 2R2, e-mail: raj.lada@dal.ca

*Corresponding author

\section{Introduction}

Balsam fir trees are a popular choice for use as Christmas trees, but postharvest needle abscission poses a challenge to the industry and to the consumers. Closely related species to balsam fir, such as Nordman fir and Fraser fir, experienced increased needle loss when water was withheld postharvest, but minimal needle loss when provided water or rehydrated before reaching a critical water potential (Mitcham-Butler et al., 1988; Chastagner \& Riley, 2003). Similar observations have been noted in 
Douglas fir, which reached a critical water potential within 12 days of harvest resulting in significant needle loss (Montano, 1985). Provision of water, greenhouse storage under humid conditions, or use of antitranspirants had various levels of success maintaining water potential and, consequently, reducing needle abscission. Dehydration has also been linked to postharvest abscission in balsam fir where a 5 -fold decrease in xylem pressure potential (XPP) and $20 \%$ decrease in relative water content occurred at the same time as accelerated abscission rates (MacDonald \& Lada, 2014). When balsam fir branches were provided water andsubjected to low vapor pressure deficit (VPD), then water status was maintained and needle retention increased approximately 5 -fold compared to branches subjected to a higher a VPD (MacDonald et al., 2012). It is reasonable to suggest that the primary biophysical trigger for postharvest needle abscission is dehydration.

The hormonal signal for postharvest needle abscission in balsam fir appears to be ethylene, which is synthesized after harvest and reached a peak prior to complete needle abscission (MacDonald et al., 2010). Prolonged exposure to exogenous ethylene triggers abscission in balsam fir even under well hydrated conditions (MacDonald et al., 2010; 2011) or when branches are stored in low VPD (MacDonald et al., 2012). The role of ethylene may be linked to dehydration, as water deficit has been shown to trigger ethylene evolution in several species (Morgan et al., 1990; Taylor \& Whitelaw, 2001). However, it should also be considered that postharvest abscission may occur independently of dehydration. In some cases, postharvest abscission has been observed in branches with a relative water content maintained above $80 \%$ and XPP maintained above -1 MPa (MacDonald et al., 2012).

Although dehydration promotes senescence and abscission in balsam fir, it may well be that there is another factor involved. It's speculated that the root detachment that occurs during harvest may deprive balsam fir branches of essential root-derived factors, which may be linked to abscission. For example, hormones such as ABA, cytokinins, and auxins in needle and root tissue have been linked to abscission in balsam fir (MacDonald \& Lada, 2014) and ABA in particular increases when branches have superior needle retention (MacDonald et al., 2014). Another potential factor could include a nutrient such as calcium, which has been shown to act as a messenger for senescence and abscission processes in many species (Poovaiah et al., 1987). One option to supplement missing root-derived factors would be to reintroduce root or xylem sap from intact balsam fir trees into postharvest trees. However, it is difficult to collect sufficient quantities of balsam fir sap. A second option would be to collect sap from a different species and introduce that to the postharvest balsam fir via the xylem. Maple sap was considered due to its availability and also because it has similar concentration of ABA to balsam fir root sap; the concentration of ABA in balsam fir roots is approximately $35 \mathrm{ng} \mathrm{g}^{-1}$ (MacDonald \& Lada, 2015, unpublished data) versus about $26 \mathrm{ng} \mathrm{g}^{-1}$ in maple sap (Schill et al., 1996) collected at the same time of the year. Concerns regarding contaminants and bacteria contributed to also introducing reverse osmosis (RO) filtration and/or autoclaving. The objective of this study is to determine the effect of xylem fed maple sap on postharvest needle retention and water status of balsam fir harvested in spring and autumn and also to determine whether autoclaving or filtering the water supply contributes to effects on needle retention and water status.

\section{Methods}

\section{Experimental design}

The experiment followed a completely randomized design with four factors: maple sap concentration, season of harvest, filtration of sap, and autoclaving of sap. Maple sap was collected from trees in Cumberland County, Nova Scotia and was diluted to 7 concentrations $(0,1,10,25,50,75$, or $100 \% \mathrm{v} / \mathrm{v})$. Balsam fir branches were harvested in either spring or autumn, sap was either filtered using reverse osmosis or not filtered, and sap was either autoclaved or not. The experiment was considered a $7 \times 2 \times 2$ $\times 2$ factorial and was replicated 5 times, using 280 branches in total.

\section{Sample collection and branch display}

Branches were harvested on April 15, 2013, and October 15, 2013. A total of 140 balsam branches were collected from an orchard in Debert, Nova Scotia, Canada. An April harvest was chosen because balsam fir harvested at this time do not exhibit any changes in abscission induced by cold acclimation (MacDonald et al., 2016). An October harvest was chosen to represent the typical time for Christmas tree harvest to begin in Nova Scotia.

A description of the orchard may be found in MacDonald et al. (2010). Each branch was cut from the most recent 2-years growth and samples were visually screened for absence of disease and nutrient deficiencies. Branches were immediately placed in a container with cut ends submerged in $\mathrm{RO}$ water for transport to agrowth room, maintained at $20^{\circ} \mathrm{C}$ and $40 \%$ humidity. Light intensity was $80 \mu \mathrm{mol} \mathrm{m}^{-2}$ $\mathrm{s}^{-1}$ supplied by fluorescent lights. All branches were initially weighed and then placed in a $100 \mathrm{~mL}$ am- 
ber bottle. Each branch was supplied a water/sap supply according to their respective treatment (i.e. maple sap dilutions, filtration, and autoclave). The neck of each bottle was sealed with cotton gauze to reduce evaporation and add stability to a branch. Afterwards, the entire assembly was weighed.

\section{Postharvest quality measurements}

Needle abscission was measured by collecting the number of needles that would fall after a 'finger run' test each day. The mass of those needles was measured fresh and after oven drying. The experiment was run until all needles had abscised (110 days for the longest lasting branches). Two time points were used to compare needle abscission patterns: needle abscission commencement (NAC) and needle retention duration (NRD). NAC was defined as the point where postharvest abscission began ( $1 \%$ needle loss) and NRD was defined as the length of time for a branch to undergo complete abscission (MacDonald et al., 2016).

Water uptake was measured gravimetrically. Each flask was weighed at the beginning of the experiment after being filled with water/sap solution and then, weekly, each branch was removed from its flask and the flask was weighed again. The difference in mass was estimated as water uptake and the rate of water uptake was calculated as:

$$
\text { Water Uptake }=\frac{M_{n}-M_{n+1}}{7 \cdot M_{b}}
$$

In the above equation water uptake is expressed as $\mathrm{mL} \mathrm{g}^{-1} \mathrm{~d}^{-1} \cdot \mathrm{M}_{\mathrm{n}}$ is the mass of the flask on any given week while $M_{n+1}$ is the mass of the flask on the subsequent week. $M_{b}$ is fresh weight of the branch. A critical value of $0.05 \mathrm{~mL} \mathrm{~g}^{-1} \mathrm{~d}^{-1}$ was established for water uptake (Lada et al., 2016) and the length of time for each branch to reach that critical water uptake rate was recorded.

The difference in fresh and dry mass of the needles was used to calculate moisture content and expressed on a fresh weight basis as below, where $M_{f}$ is the fresh mass of needles and $M_{d}$ is the dried mass of needles:

$$
\% \text { Moisture }=\frac{M_{f}-M_{d}}{M_{f}} \times 100
$$

Two critical values of moisture content were identified. The first was called MC Lag, which was the length of time branches maintained moisture content above $50 \%$. On a graph, moisture content decreased very slowly until it reached $50 \%$. After decreasing to $50 \%$, moisture content would follow a steeper rate of decline (MacDonald et al., 2016). The other critical value was Ignition $\mathrm{MC}$, which was the length of time required for a branch to become dry enough that a match could catch a branch on fire (33\%) (van Wagner, 1991).

\section{Maple sap hormone analysis}

Four combinations of maple sap were prepared for hormone analysis: unfiltered/not autoclaved, RO filtered/not autoclaved, unfiltered/autoclaved, and RO filtered/autoclaved. All maple sap samples were stored at $-80^{\circ} \mathrm{C}$ after collection until hormone analysis.

Analysis was performed on a UPLC/ESI-MS/MS utilizing a Waters ACQUITY UPLC system, equipped with a binary solvent delivery manager and a sample manager coupled to a Waters Micromass Quattro Premier XE quadrupole tandem mass spectrometer via a Z-spray interface located at the Plant Biotechnology Institute of the National Research Council of Canada (NRC, Saskatoon, SK, Canada). MassLynx ${ }^{\mathrm{TM}}$ and QuanLynx ${ }^{\mathrm{TM}}$ (Micromass, Manchester, UK) were used for data acquisition and analysis.

Several metabolite standards were synthesized and prepared atNRC. Other standards were purchased from Sigma-Aldrich, Olchemim Ltd. (Olomouc, Czech Republic)or the Research School of Chemistry, Australian National University, Canberra, AU. Deuterated forms of the hormones, which were used as internal standards, were synthesized according to Abrams et al. (2003) and Zaharia et al. (2005). Calibration curves were created for all compounds of interest. Quality control samples were run along with the samples.

A $100 \mu \mathrm{L}$ aliquot containing all the internal standards, each at a concentration of $0.2 \mathrm{pg} \mu \mathrm{L}^{-1}$ was added to $50 \mathrm{mg}$ of homogenized sample. An extraction mixture containing $3 \mathrm{~mL}$ of isopropanol: water: glacial acetic acid (80:19:1, v/v) was then added, and the samples were agitated in darkness for $24 \mathrm{~h}$ at $4^{\circ} \mathrm{C}$. Following centrifugation, the supernatant was isolated and dried on a Büchi Syncore Polyvap (Büchi, Switzerland). Samples were reconstituted in $100 \mu \mathrm{L}$ of acidified methanol, adjusted to $1 \mathrm{~mL}$ with acidified water, and then partitioned against $2 \mathrm{~mL}$ hexane. After $30 \mathrm{~min}$ the aqueous layer was isolated and dried as described above. Dry samples were reconstituted in $800 \mu \mathrm{L}$ acidified methanol and adjusted to 1 $\mathrm{mL}$ with acidified water. The reconstituted samples were passed through equilibrated Sep-Pak 200 C18 cartridges (Waters, Mississauga, ON, Canada) and then dried on a LABCONCO centrivap concentrator (Labconco Corporation, Kansas City, MO, USA). An internal standard blank was prepared with $100 \mu \mathrm{L}$ of the deuterated internal standards mixture and a quality control standard was prepared by adding 100 $\mu \mathrm{L}$ of a mixture containing all the analytes of interest, 
Table 1. Comparison of ABA and present metabolites in raw maple sap versus maple sap which was submitted to reverse osmosis. Data are expressed as mean \pm standard error as calculated from 6 replicates

\begin{tabular}{|c|c|c|c|c|c|c|c|c|c|c|c|c|c|c|}
\hline \multirow{3}{*}{$\frac{\text { Treatment }}{\text { Raw Sap }}$} & \multicolumn{14}{|c|}{ Concentration (ng $\cdot \mathrm{g}^{-1}$ fresh sap weight) } \\
\hline & \multicolumn{3}{|c|}{$\mathrm{c}-\mathrm{ABA}$} & \multicolumn{3}{|c|}{ DPA } & \multicolumn{3}{|c|}{ PA } & \multicolumn{3}{|c|}{ OH-ABA } & \multicolumn{2}{|c|}{$\mathrm{t}-\mathrm{ABA}$} \\
\hline & 18.0 & \pm & 4.5 & 69.0 & \pm & 22.8 & 163.0 & \pm & 2.3 & 7.7 & \pm & 2.3 & 3.6 & 0.1 \\
\hline RO Sap & 3.6 & \pm & 0.1 & 2.1 & \pm & 2.9 & 8.3 & \pm & 0.2 & 1.8 & \pm & 2.5 & \multicolumn{2}{|c|}{ not detected } \\
\hline P-value & \multicolumn{3}{|c|}{$=0.001$} & \multicolumn{3}{|c|}{$=0.001$} & \multicolumn{3}{|c|}{$<0.001$} & \multicolumn{3}{|c|}{$=0.002$} & \multicolumn{2}{|c|}{$\mathrm{n} / \mathrm{a}$} \\
\hline
\end{tabular}

each at a concentration of $0.2 \mathrm{pg} \mu \mathrm{L}^{-1}$, to $100 \mu \mathrm{L}$ of the internal standard mix. Finally, samples, blanks, and quality controls were reconstituted in a solution of $40 \%$ methanol $(\mathrm{v} / \mathrm{v})$, containing $0.5 \%$ acetic acid and $0.1 \mathrm{pg} \mu \mathrm{L}^{-1}$ of each of the recovery standards.

The procedure for quantification of multiple hormones and metabolites has been described in detail by Chiwocha et al. (2003, 2005). Samples were injected onto a Genesis C18 HPLC column $(100 \times 2.1$ $\mathrm{mm}, 4 \mu \mathrm{m}$, Chromatographic Specialties, Brockville, ON, Canada) and separated by a gradient elution of water against an increasing percentage of acetonitrile that contained $0.04 \%$ acetic acid. Calibration curves were generated from the multiple reaction monitoring signals obtained from standard solutions based on the ratio of the chromatographic peak area for each analyte to that of the corresponding internal standard, as described by Ross et al. (2004).

\section{Maple sap mineral analysis}

Mineral analysis of the maple sap was performed by the Institute of Research and Development in Agri-Environment Laboratory (Quebec, Canada). The analytical procedure consisted of acidifying a 2.5 g sample of maple sap with $0.5 \mathrm{~mL}$ of $70 \%$ nitric acid and then adjusting the volume to $50 \mathrm{~mL}$. Samples were centrifuged, filtered through a $0.45 \mathrm{~mm}$ membrane and analyzed by ICP/OES, optima 430 (PerkinElmer Woodbridge, ON, Canada). The wavelengths $(\mathrm{nm})$ applied for different elements were as follows: K (766.490), Ca (315.887), Mg (279.077), $\mathrm{Mn}$ (257.610), Na (589.592) and $\mathrm{Zn}$ (213.857). The standard solutions Multi-Element (900-Q21002 Plasma CAL), Plasma CAL-Fe (10,000 mg/L) and Plasma CAL-S (1000 mg/L) were purchased from SCP Science (Canada) and used for calibration curves.

\section{Statistical Analysis}

Maple sap hormone concentrations were submitted to an analysis of variance using autoclaving and filtration as explanatory variables. Autoclaving had no effect on hormone concentrations, so the replicates were pooled and analyzed as a 2-sample t-test. All critical postharvest values (NAC, NRD, Critical WU, Ignition MC, and MC Lag)were submitted to an analysis of variance to determine the effect of harvest season, maple sap concentration, filtration, and autoclaving. Means were then separated using Tukey's method at a $5 \%$ significance level.In each test, statistical assumptions for normality, homogeneity, and independence were validated. All statistical analysis was completed using Minitab 17 (Minitab Inc., State College, PA, USA).

\section{Results}

\section{Maple sap composition}

ABA and its metabolites were found in all samples of maple sap (Table 1). Autoclaving made no difference in $\mathrm{ABA}$ concentrations, but the concentration of ABA and its metabolites was significantly lower in sap submitted to RO. The primary metabolite present in maple sap was PA at $163.0 \mathrm{ng} \mathrm{g}^{-1}$, but it was $95 \%$ lower in RO sap. There was an $80 \%$ decrease in ABA, $97 \%$ decrease in DPA, and $77 \%$ decrease in $\mathrm{OH}-\mathrm{ABA}$ resulting from $\mathrm{RO}$. In addition, $\mathrm{t}-\mathrm{ABA}$ decreased from $3.6 \mathrm{ng} \mathrm{g}^{-1}$ to concentrations below the detectable limit after RO. Cytokinins, auxins, and gibberellins were all below detectable limits in maple sap.

Mineral analysis detected phosphorus, potassium, calcium, magnesium, sodium, aluminum, copper, zinc, and manganese in maple sap (Table 2). Autoclaving made no difference in mineral concentrations, but several minerals were significantly lower in sap submitted to RO. There was a $23 \%$ decrease in potassium, $29 \%$ decrease in calcium, $33 \%$ decrease

Table 2. Comparison of $\mathrm{pH}$ and minerals in raw maple sap versus maple sap that was submitted to reverse osmosis

\begin{tabular}{lcc}
\hline \multicolumn{1}{c}{ Parameter } & RO & Sap \\
\hline $\mathrm{pH}$ & 4.90 & 5.09 \\
$\mathrm{P}(\mathrm{ppb})$ & 234 & 243 \\
$\mathrm{~K}(\mathrm{mg} / \mathrm{kg})$ & 24.4 & 31.5 \\
$\mathrm{Ca}(\mathrm{mg} / \mathrm{kg})$ & 7.96 & 11.2 \\
$\mathrm{Mg}(\mathrm{mg} / \mathrm{kg})$ & 1.42 & 2.11 \\
$\mathrm{Na}(\mathrm{mg} / \mathrm{kg})$ & 1.79 & 1.4 \\
$\mathrm{Al}(\mathrm{mg} / \mathrm{kg})$ & 0.037 & 0.109 \\
$\mathrm{~B}(\mathrm{mg} / \mathrm{kg})$ & 0 & 0 \\
$\mathrm{Cu}(\mathrm{mg} / \mathrm{kg})$ & 0.027 & 0.02 \\
$\mathrm{Fe}(\mathrm{mg} / \mathrm{kg})$ & 0.025 & 0.015 \\
$\mathrm{Zn}(\mathrm{mg} / \mathrm{kg})$ & 0.136 & 0.103 \\
$\mathrm{Mn}(\mathrm{mg} / \mathrm{kg})$ & 1.02 & 1.49 \\
\hline
\end{tabular}


magnesium, $64 \%$ decrease in aluminum, and 32\% decrease in manganese in $\mathrm{RO}$ sap compared to raw sap.

\section{Needle abscission}

There was a significant interaction effect between season and filtration on NAC $(\mathrm{P}=0.033)$ and NRD $(\mathrm{P}<0.001)$ (Table 3$)$. The interaction effect on NAC and NRD was similar, where there was no difference in NAC or NRD of spring harvested branches due to filtration. However, the NAC and NRD of autumn harvested branches were significantly higher when branches were supplied a water/sap source that had not undergone RO. Autumn harvested branches had a $41 \%$ higher NAC and a $72 \%$ higher NRD when provided a water/sap supply that had not undergone RO. Further, any seasonal effect on NRD was reversed when the water/sap supply had undergone RO; autumn harvested branches had higher NRD than spring harvested branches when placed in water/sap supply that had not undergone RO but lower NRD than spring harvested branches in a water/sap supply that had undergone RO.

There was also a significant interaction effect between maple sap concentration and filtration on NAC $(\mathrm{P}=0.037)$ and NRD $(\mathrm{P}=0.004)$ (Fig. 1). Overall, the trend is that needle retention decreased as the concentration of sap increased. For example, pure water resulted in an average NAC of 41.7 days and NRD of 61.0 days, but pure maple sap resulted in an average NAC of 9.9 days ( $74 \%$ decrease) and NRD of 28.8 days (53\% decrease). The interaction effect in NAC is likely due to the fact that branches placed in pure water took longer to begin losing needles than branches placed in water which had not been filtered, while most treatments performed better without RO. The interaction effect NRD is likely due to a similar phenomenon, where there was a much faster decline in NRD in branches placed in treatments which had undergone RO.

\section{Water uptake}

There was a significant $(P<0.001)$ interaction effectbetween season and filtration on the length of time to reach a critical water uptake rate (Table 3).

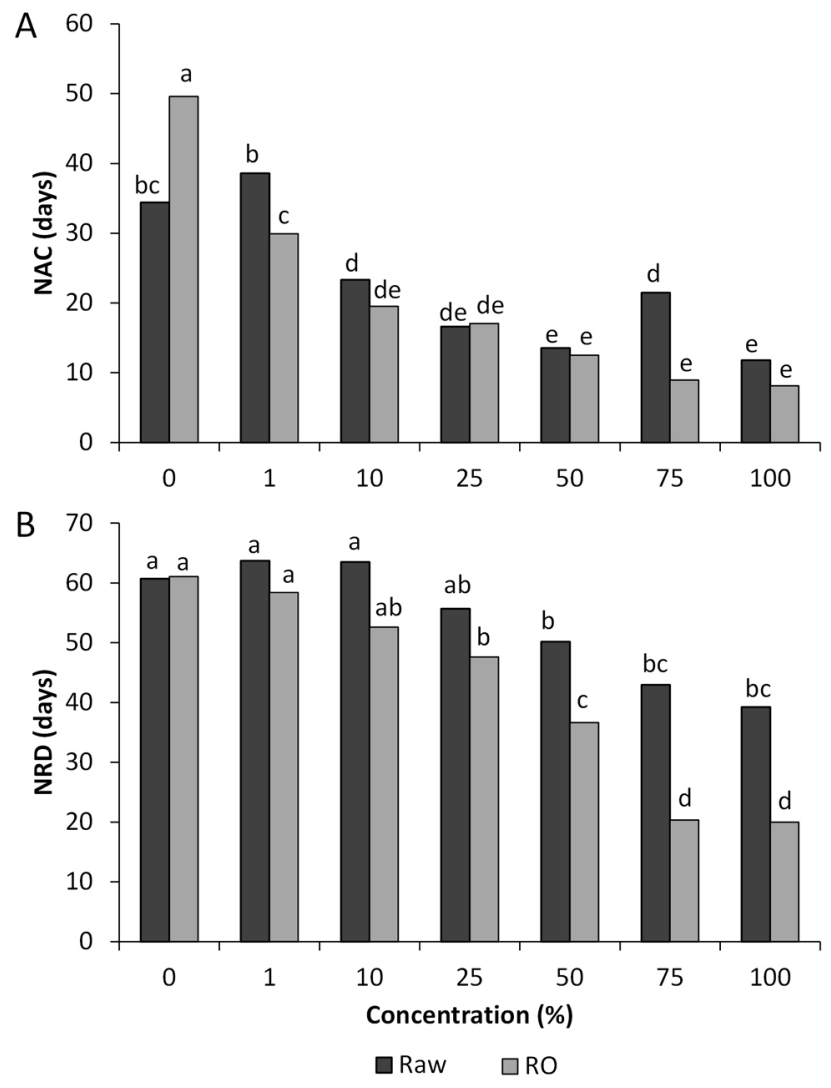

Fig. 1. Interaction of sap concentration and sap filtration on needle retention of balsam fir branches, as determined by A) needle abscission commencement and B) needle retention duration. Means in each treatment combination were calculated from 20 branches. Bars with different letters were determined to be significantly different at the $5 \%$ significance level using Fisher's least significant differences comparison

Though there was no difference in the length of time to reach a critical water uptake in spring harvested branches, autumn harvested branches took $46 \%$ longer to reach a critical uptake rate when supplied raw sap in a water solution. Also, branches supplied raw sap in solution took longer to reach a critical uptake rate in autumn compared to spring; branches supplied with sap that had undergone RO took longer to reach a critical uptake rate in spring compared to autumn.

There was also a significant $(\mathrm{P}=0.032)$ interaction effect between sap concentration and autoclaving sap solution (Fig. 2). The overall trend was that

Table 3. Effect of harvest season and type of sap filtration on the number of days to reach several postharvest parameters in balsam fir. Means were calculated from 70 replicates and means separated using Fisher's least significant difference mean comparison. $\mathrm{NAC}=$ needle abscission commencement, $\mathrm{NRD}=$ needle retention duration, $\mathrm{WU}=$ critical water uptake, MC Lag = moisture content lag, and Ignition MC = ignition point moisture content

\begin{tabular}{|c|c|c|c|c|c|c|c|c|c|c|c|}
\hline \multirow{2}{*}{$\begin{array}{l}\text { Season } \\
\text { Spring }\end{array}$} & \multirow{2}{*}{$\begin{array}{c}\text { Filtration } \\
\text { Raw }\end{array}$} & \multicolumn{2}{|c|}{ NAC } & \multicolumn{2}{|c|}{ NRD } & \multicolumn{2}{|c|}{ WU } & \multicolumn{2}{|c|}{ MC Lag } & \multicolumn{2}{|c|}{ Ignition MC } \\
\hline & & 19 & $\mathrm{~b}$ & 44 & $\mathrm{~b}$ & 16 & $\mathrm{bc}$ & 32 & $\mathrm{bc}$ & 42 & $\mathrm{~b}$ \\
\hline \multirow{3}{*}{ Autumn } & RO & 20 & $a b$ & 45 & $\mathrm{~b}$ & 18 & $a b$ & 33 & $\mathrm{~b}$ & 43 & $\mathrm{~b}$ \\
\hline & Raw & 25 & $\mathrm{a}$ & 63 & a & 20 & $\mathrm{a}$ & 45 & $\mathrm{a}$ & 56 & $\mathrm{a}$ \\
\hline & $\mathrm{RO}$ & 18 & $\mathrm{~b}$ & 37 & $\mathrm{c}$ & 13 & $\mathrm{C}$ & 27 & c & 37 & $\mathrm{C}$ \\
\hline
\end{tabular}




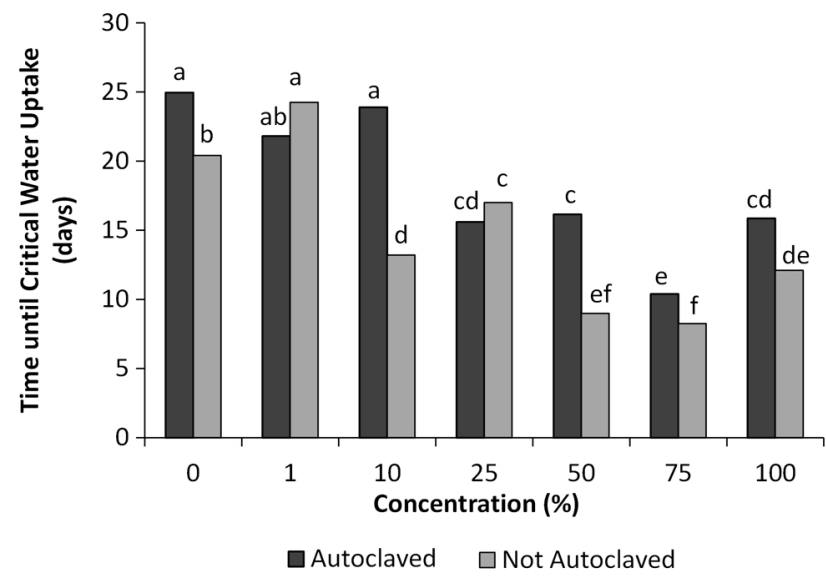

Fig. 2. Interaction between autoclaving and sap concentration on the length of time to reach a $0.05 \mathrm{~mL} \mathrm{~g}^{-1} \mathrm{~d}^{-1}$ water uptake rate in balsam fir. Means in each treatment combination were calculated from 70 branches. Bars with different letters were determined to be significantly different at the 5\% significance level using Fisher's least significant differences comparison

as the sap concentration increased, then the time to reach critical water uptake rates decreased. The other trend was that autoclaving the sap never sig-
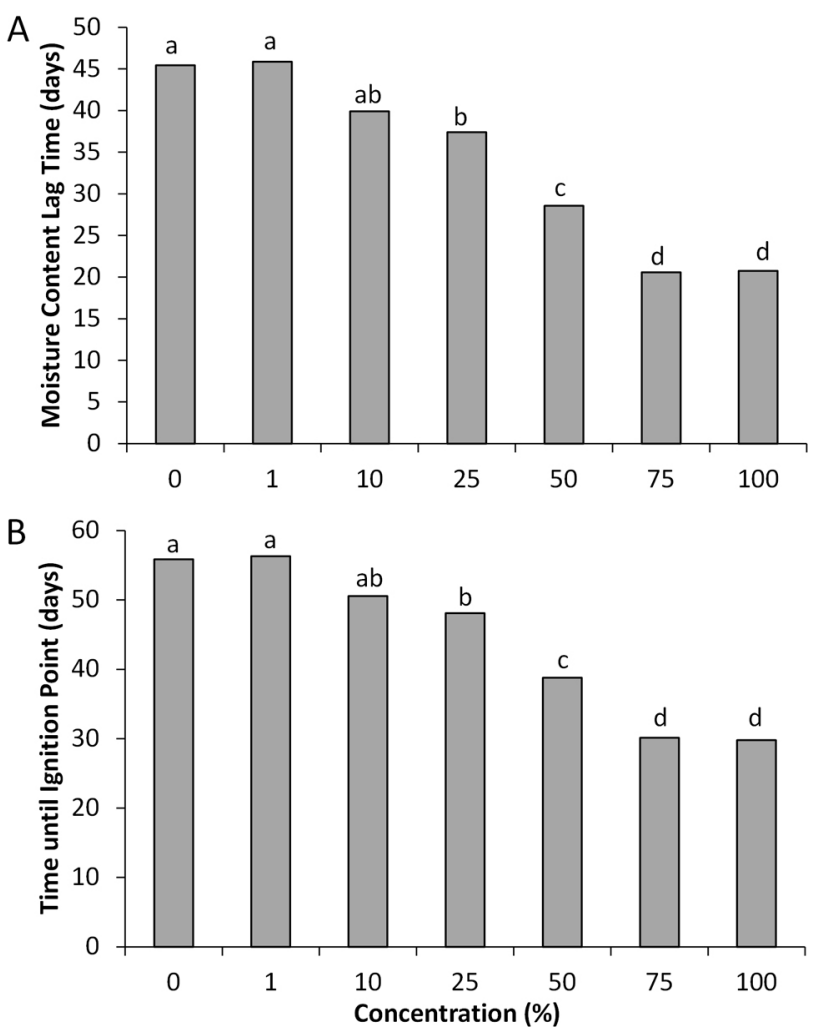

Fig. 3. Effect of maple sap concentration on A) the length of time to fall below $50 \%$ moisture content and B) the length of time to reach ignition point (33\% moisture content). Means in each treatment combination were calculated from 40 branches. Bars with different letters were determined to be significantly different at the $5 \%$ significance level using Fisher's least significant differences comparison nificantly decreased the length of time until critical uptake - there was either an increase or no significant difference.

\section{Water content}

Maple sap concentration had a significant $(\mathrm{P}<$ 0.001) effect on the branch moisture content lag time and the length of time to reach ignition point (Fig. 3). The trend for each variable was similar. When branches were fed pure water, the moisture content in branches was maintained above $50 \%$ for 45.5 days, which had significantly decreased to 37.4 days at a maple sap concentration of $25 \%$. When branches were fed pure map sap, the moisture content in branches was maintained above $50 \%$ for only 20.8 days. Similarly, the length of time for branches to reach ignition point when fed pure water was 55.9 days and significantly decreased when maple sap concentration was $25 \%$ or higher. The length of time for branches to reach ignition point when fed pure maple sap was only 29.8 days.

There was a significant $(P<0.001)$ interaction effect between season and filtration on moisture content lag time and length of time to reach ignition point (Table 3 ). In each case, water content was maintained longer in autumn when supplied sap that had not undergone RO. The water content lag time and time to reach ignition point was lower in autumn compared to spring when branches were fed sap that had undergone RO.

\section{Discussion}

The concentration of ABA in maple sap used in this experiment was $18.0 \mathrm{ng} \mathrm{g}^{-1}$. Schill et al. (1996) reported average values between 16.8 and $26.4 \mathrm{ng} \mathrm{g}^{-1}$ in maple sap while noting that there was variation in the concentration based on height of collection. Davison and Young (1973) reported that a significant amount of ABA is converted into t-ABA, presumably due to the collection and purification methods associated with sap. However, there was very little t-ABA present in our experiment, possibly due to the fact that our samples were collected fresh and not submitted to the purification process it would undergo if being prepared as syrup. The concentrations of ABA metabolites such as DPA and PA were present at much higher concentrations than ABA.

There has been some link between ABA and needle abscission in balsam fir in the past. Balsam fir trees accumulate ABA in autumn months which coincides with superior needle retention (MacDonald et al., 2014; Thiagarajan et al., 2013). Further, exposure to low temperatures induced ABA while simultaneously delaying postharvest needle abscission in 
balsam fir (Thiagarajan et al., 2013). A separate study confirmed a strong positive correlation between $\mathrm{ABA}$ and postharvest needle retention (MacDonald \& Lada, 2015, unpublished results). Conversely, it was shown that ABA increases approximately 50fold during abscission (MacDonald \& Lada, 2014), though it was speculated that ABA was ultimately beneficial to postharvest balsam fir by helping to conserve water.

It was hypothesized that xylem fed maple sap would delay postharvest abscission, either through introducing exogenous ABA or through some other unknown root derived factor. This hypothesis proved to be incorrect as ultimately there was no significant benefit to needle retention or water status from any concentration of maple sap. At best, low concentrations of maple sap $(<25 \%)$ did not decrease the length of time required to complete abscission. However, even concentrations of maple sap as low as $10 \%$ significantly decreased the length of time to commence abscission compared to that of a control. This should not be due to maple sap not being moved through the xylem, as even pure maple sap was consumed at rates above $0.05 \mathrm{~mL} \mathrm{~g}^{-1} \mathrm{~d}^{-1}$ for over two weeks. With respect to ABA, it is possible that the concentrations present in maple sap were simply not of sufficient concentration to confer any benefit. The concentration of ABA in raw sap was only $18 \mathrm{ng}$ $\mathrm{g}^{-1}$, while concentrations in balsam fir with superior needle retention ranged from approximately 90 to $250 \mathrm{ng} \mathrm{g}^{-1}$ in roots and 2000 to $5000 \mathrm{ng} \mathrm{g}^{-1}$ in shoots (Thiagarajan et al., 2012; MacDonald \& Lada, 2015, unpublished results).

It is relevant to note that branches provided with higher concentrations of maple sap tended to reach the critical value of water uptake of $0.05 \mathrm{~mL} \mathrm{~g}^{-1} \mathrm{~d}^{-1}$ faster than the branches provided with low concentrations of sap. This translates directly into decreased water content and increased needle abscission. While the exact reason for this is unknown, it is possible that it may be due to bacterial growth in the water supply. Lada et al. (2016) demonstrated that bacterial counts increase exponentially in Christmas tree stands, which could easily be accelerated by the high sugar content of maple sap. Autoclaving the sap seemed to help branches maintain higher levels of water consumption for a longer period of time, though bacteria could still be introduced from the branches themselves. Regardless, even the slight improvement to water consumption did not translate to a significant increase in water content.

There was an interesting trend for needle retention and water content of branches to be improved in autumn compared to spring if provided with sap, which had not undergone RO filtration. Several studies have found that postharvest needle abscission of fir trees, such as Fraser and balsam, increases in autumn (Chastagner \& Riley, 2007; MacDonald et al., 2014; Mitcham-Butler et al., 1988). However, our study found that the increase in needle retention in autumn harvested branches was reversed when provided RO filtered sap. There's certainly an argument to be made that RO effectively decreased the concentration of ABA in maple sap (95\% decrease in PA, $80 \%$ decrease in ABA, 97\% decrease in DPA, and $77 \%$ decrease in $\mathrm{OH}-\mathrm{ABA})$. Further, minerals such as potassium, calcium, magnesium, aluminum, and manganese were also lower after RO. It is possible that RO removed factors essential to superior postharvest needle retention of branches harvested in autumn.

In conclusion, maple sap was not an effective additive to water supplies to delay abscission or maintain water content. RO filtration of the sap also tended to have a negative effect, even negating the expected seasonal increase in needle retention from spring to autumn suggesting a potential factor, possibly a mineral element, when removed through RO process, could be detrimental to needle retention. Autoclaving the sap helped maintain higher levels of water consumption, but that was unable to translate benefits to improving needle retention or water content.

\section{References}

Abrams SR, Nelson K \& Ambrose SJ (2003) Deuterated abscisic acid analogs for mass spectrometry and metabolism studies. Journal of Label Compounds \& Radiopharmaceuticals 46: 273-283.

Chastagner G \& Riley K (2003) Postharvest quality of noble and Nordmann fir Christmas trees. Hortscience 38: 419-421.

Chastagner G \& Riley K (2007) Solving the needle loss nuisance - Christmas tree research examines the effect of harvest date on true fir needle retention. Great Lakes Christmas Tree Journal 2: 36-39.

Chiwocha SDS, Abrams SR, Ambrose SJ, Cutler AJ, Loewen M, Ross ARS \& Kermode AR (2003) A method for profiling classes of plant hormones and their metabolites using liquid chromatography electrospray ionization tandem mass spectrometry: an analysis of hormone regulation of thermodormancy of lettuce (Lactuca sativa L.) seeds. The Plant Journal 35: 405-417.

Chiwocha SDS, Cutler AJ, Abrams SR, Ambrose SJ, Yang J, Ross ARS \& Kermode AR (2005) The etr 1 2 mutation in Arabidopsis thaliana affects the abscisic acid, auxin, cytokinin and gibberellin metabolic pathways during maintenance of seed dormancy, moist chilling and germination. The Plant Journal 42: 35-48.

Davison RM \& Young H (1973) Abscisic-acid content of xylem sap. Planta 109: 95-98. 
Lada RR, MacDonald MT \& West RR (2016) Physiology of postharvest needle abscission in balsam fir: water quality modulates postharvest needle abscission. Acta Horticulturae 1119: 111-120.

MacDonald MT \& Lada RR (2014) Biophysical and hormonal changes linked to postharvest needle abscission in balsam fir. Journal of Plant Growth Regulation 33: 602-611.

MacDonald MT, Lada RR, Dorais M \& Pepin S (2012) Influence of humidity and temperature on postharvest needle abscission in balsam fir in the presence and absence of exogenous ethylene. Hortscience 47: 1328-1332.

MacDonald MT, Lada RR, Martynenko AI, Dorais M, Pepin S \& Desjardins Y (2010) Ethylene triggers needle abscission in root-detached balsam fir. Trees 24: 879-886.

MacDonald MT, Lada RR, Martynenko AI, Dorais M, Pepin S \& Desjardins Y (2011) Ethylene exposure duration affects postharvest needle abscission in balsam fir (Abies balsamea L.). Hortscience 46: 260-264.

MacDonald MT, Lada RR \& Veitch RS (2016) Seasonal changes in balsam fir needle abscission patterns and links to environmental factors. Scandinavian Journal Forest Research. In press.

MacDonald MT, Lada RR, Veitch RS, Thiagarajan A \& Adams AD (2014) Postharvest needle abscission resistance of balsam fir (Abies balsamea) is modified by harvest date. Canadian Journal of Forest Research 44: 1394-1401.

Mitcham-Butler EJ, Hinesley LE \& Pharr DM (1988) Effects of harvest date, storage temperature, and moisture status on postharvest needle retention of Fraser fir. Journal of Environmental Horticulture 6: 1-4.

Montano JM (1985) Postharvest water relations and needle abscission in cut trees of Douglas fir (Pseudotsuga menziesii Mirb. Franco). PhD Thesis, Oregon State University, Oregon, USA.

Morgan PW, He CJ, De Greef JA \& De Proft MP (1990) Does water deficit stress promote ethyl- ene synthesis by intact plants? Plant Physiology 94: 1616-1624.

Poovaiah BW, Reddy ASN \& Leopold AC (1987) Calcium messenger system in plants. Critical Reviews in Plant Sciences 6: 47-103.

Ross ARS, Ambrose SJ, Cutler AJ, Allan Feurtado J, Kermode AR, Nelson K, Zhou R \& Abrams SR (2004) Determination of endogenous and supplied deuterated abscisic acid in plant tissues by high-performance liquid chromatography-electrospray ionization tandem mass spectrometry with multiple reaction monitoring. Analytical Biochemistry 329: 324-333.

Schill V, Hartung W, Orthen B \& Weisenseel MH (1996) The xylem sap of maple (Acer platanoides) trees - sap obtained by a novel method shows changes with season and height. Journal of Experimental Botany 47: 123-133.

Taylor JE \& Whitelaw CA (2001) Signals in abscission. New Phytologist 151: 323-340.

Thiagarajan A, Lada R, Pepin S, Forney C, Desjardins Y, Dorais M (2012) Characterization of phytohormonal and postharvest senescence responses of balsam fir (Abies balsamea (L.) Mill.) exposed to short-term low temperatures. Trees 26: 15451553.

Thiagarajan A, Lada R, Pepin S, Forney C, Desjardins Y \& Dorais M (2013) Temperature and photoperiod influence postharvest needle abscission of selected balsam fir (Abies balsamea L. (Mill.)) genotypes by modulating ABA levels. Journal of Plant Growth Regulation 32: 843-851.

Van Wagner CE (1991) Moisture content and inflammability in spruce, fir, and Scots pine Christmas trees. Technical Note No. 109, Forest Research Branch, Department of Forestry, Canada.

Zaharia LI, Walker-Simmon MK, Rodriguez CN \& Abrams SR (2005) Chemistry of abscisic acid, abscisic acid catabolites and analogs.Journal of Plant Growth Regulation 24: 274-284. 